\title{
Conocimientos, actitudes y prácticas sobre la lactancia materna exclusiva, en madres lactantes con niños menores de un año, INMP-2011
}

Elsy Mini, Joece Butron, Lesly Aquino, Liz Castro, Elsa Cerrón, Emily Díaz, Alexander Fernández, Elsie Mendoza, Nélida Quispe, Pamela Sacsara, Yeraldine Tarco, Vanessa Vílchez

Facultad de Medicina, UNMSM, e Instituto Nacional Materno Perinatal, Lima, Perú

Objetivos: Determinar el nivel de conocimientos, actitudes y prácticas sobre lactancia materna exclusiva, en madres de niños lactantes menores de un año.

Diseño: Estudio descriptivo, trasversal.

Institución: Facultad de Medicina, UNMSM, e Instituto Nacional Materno Perinatal, Lima, Perú.

Participantes: Madres de niños lactantes menores de un año.

Intervenciones: Aplicación de entrevista CAP a 173 madres. Prueba piloto con validación instrumentos.

Principales medidas de resultados: Se determinó el nivel de conocimientos, actitudes y prácticas y perfil sociodemográfico.

Resultados: El $67,6 \%$ de participantes fue adulta joven, $58,4 \%$ conviviente, $71,7 \%$ con estudios secundarios y $74,6 \%$ amas de casa. El 60,7\% recibió consejería sobre lactancia materna; $61 \%$ tuvo un nivel de conocimiento medio sobre lactancia materna exclusiva. Solo el $31 \%$ tenía conocimientos sobre la forma correcta de amamantar. El $47 \%$ estuvo de acuerdo con la lactancia materna exclusiva hasta los 6 meses de edad. El 61\% de las participantes se sentía parcialmente motivada cuando lactaba a su niño y existió un $20 \%$ de ellas que estaba de acuerdo con algunos mitos. El $54,9 \%$ inició la lactancia materna inmediatamente después del parto.

Conclusiones: Es necesario afianzar conocimientos y revalorizar la confianza en los beneficios de la lactancia materna exclusiva.

Palabras clave: Lactancia materna, conocimientos, actitudes, prácticas.

\section{Evaluación de los niveles de estrés crónico del recurso humano de la Microrred de Pachacamac, mayo 2012}

Noemí Collado, Jazmín Figueroa

Facultad de Medicina, UNMSM

Objetivos: Medir los niveles de estrés crónico en el recurso Humano de la Microrred de Pachacamac. Definir la relación entre los niveles de satisfacción laboral y los niveles de estrés o agotamiento. Comparar los niveles de estrés entre los trabajadores asistenciales y administrativos.

Diseño: Estudio descriptivo, trasversal.

Institución: Facultad de Medicina, UNMSM.

Participantes: Trabajadores de salud.

Intervenciones: En 54 trabajadores de salud -8 administrativos, 42 asistenciales y 4 que no especificaron funciónse llevó a cabo una intervención de evaluación, capacitación y dinámicas de integración del recurso humano de la Microrred de Pachacamac. Participaron 22 de los alumnos del quinto año de Medicina Humana de la UNMSM, que llevaban el curso de Psiquiatría en la sede del Hospital Víctor Larco Herrera. Se aplicó la Escala de Maslach, la que respondieron en 15 minutos.

Principales medidas de resultados: Estrés.

Resultados: De la población estudiada, 3,7\% evidenció bajo nivel de estrés crónico; de estos, el 100\% era asistencial. El $63 \%$ evidenció niveles de estrés moderado; de estos $76,5 \%$ era personal asistencial, $14,7 \%$ administrativo y $8,8 \%$ no especificó labor; $33,3 \%$ presentó niveles de estrés severo; de estos, $77,8 \%$ era asistencial, $16,7 \%$ administrativo y $5,5 \%$ no especificó tipo de labor.

Conclusiones: El personal que trabajaba más de cerca con los pacientes estuvo más expuesto a presentar niveles mayores de ansiedad y esto influyó en su rendimiento laboral y sus relaciones interpersonales.

Palabras clave: Estrés laboral, escala Maslach. 